\title{
New Diagrams and Applications for the Wire Zone-Border Zone Approach to Vegetation Management on Electric Transmission Line Rights-of-Way
}

\author{
Benjamin D. Ballard, Kevin T. McLoughlin, and Christopher A. Nowak
}

The wire zone-border zone (WZ/BZ) approach to vegetation management on electric transmission line rights-of-way (ROWs) was formally introduced by Drs. Bramble and Byrnes in the mid-1980s (Bramble et al. 1985, 1986). It is a siteexplicit way of dividing the ROW width into three distinct management zones from edge to edge: the border zone, the wire zone, and another border zone (Figure 1). In this classical WZ/BZ approach, the ROW vegetation is managed differently in the two basic zones, purportedly to optimize the safe and reliable transmission of electricity. Herb-grass-forb cover types (low-growing vegetation), which may include some very short woody shrubs (oftentimes all woody shrubs are excluded), are promoted in the wire zone; whereas shrubshort tree cover types (taller woody vegetation) are allowed to grow in the border zones (Ballard et al. 2004; Yahner and Hutnik 2004). The WZ/BZ approach is also touted to ensure that other values are consistently, predictably produced on ROWs, including aesthetics, wildlife habitat (as exemplified by Bramble, Byrnes, and Yahner's Pennsylvania State Game Lands 33 research; e.g., Bramble et al. 1985, 1986; Yahner et al. 2004), biodiversity, and lower long-term vegetation management costs.

Recently, the U.S. Federal Energy Regulatory Commission (FERC) and the North American Electric Reliability Corporation effectively endorsed the use of the WZ/BZ for management of ROW vegetation (www.nerc.com/ filez/standards/ Vegetation-Management.html; Standard FAC-003-1) by recognizing the American National Standards Institute (ANSI) A300 Tree Care Operations standards as an "industry best practice" (the WZ/BZ approach was also presented as a Best Management Practice in the Final Vegetation Management Report to FERC on the 14 August 2003 blackout; CN Utility Consulting 2004). Promotion of the WZ/BZ approach is clear in the ANSI A300 Part 7-2006 Integrated Vegetation Management standards (ANSI 2006). In the ANSI standards and other recent portrayals of the WZ/BZ approach (Nowak et al.
2002; Nowak and Appelt 2002; Ballard et al. 2004; Yahner et al. 2004), the original Bramble et al. (1985, 1986) diagram was commonly used as a basis for both describing and illustrating the approach (Figure 1A). This original WZ/BZ diagram was useful for introducing the initial concept, but our recent efforts to use the WZ/BZ approach in research, development, and technology transfer identified two critical shortfalls: 1) the diagram was not to usual, operational scale, because the two border zones (approximately $60 \%$ of ROW width in the Bramble et al. diagram) were much larger than is normal for operating ROWs, resulting in a depiction of an unusually wide ROW; and 2) the two-dimensional crosssection of the ROW oversimplified real-world ROW conditions, in which WZ conductor-to-ground distances vary as a function of conductor sag (position between tower structures) and sway and site topography. Inaccuracies and oversimplification in the original Bramble et al. diagram can affect how the WZ/BZ approach is interpreted and implemented. We have redrawn the WZ/BZ diagram to be more consistent with actual field operations (Figure 1B). We have also fashioned representative plan and profile views to produce a more realistic and spatially explicit, three-dimensional illustration of ROW conditions in relation to WZ/BZ boundaries (Figure 2) so as to provide a more flexible and practical interpretation of the WZ/BZ approach for application to modern, integrated ROW vegetation management.

The plan and profile views (Figure 2), when used in conjunction with the cross-section view (Figure 1B), provide a three-dimensional image of a ROW, which demonstrates that not all of the ROW area under the conductors needs to be treated as "wire zone" (i.e., to exclude all woody vegetation). For example, on level sites, the conductors are closer to the ground at midspan (conductor sag and sway are a concern), but ROW areas directly under the conductors and closer to tower structures may provide sufficient ground-to-conductor clearance to permit retaining typical "border zone" vegeta- 

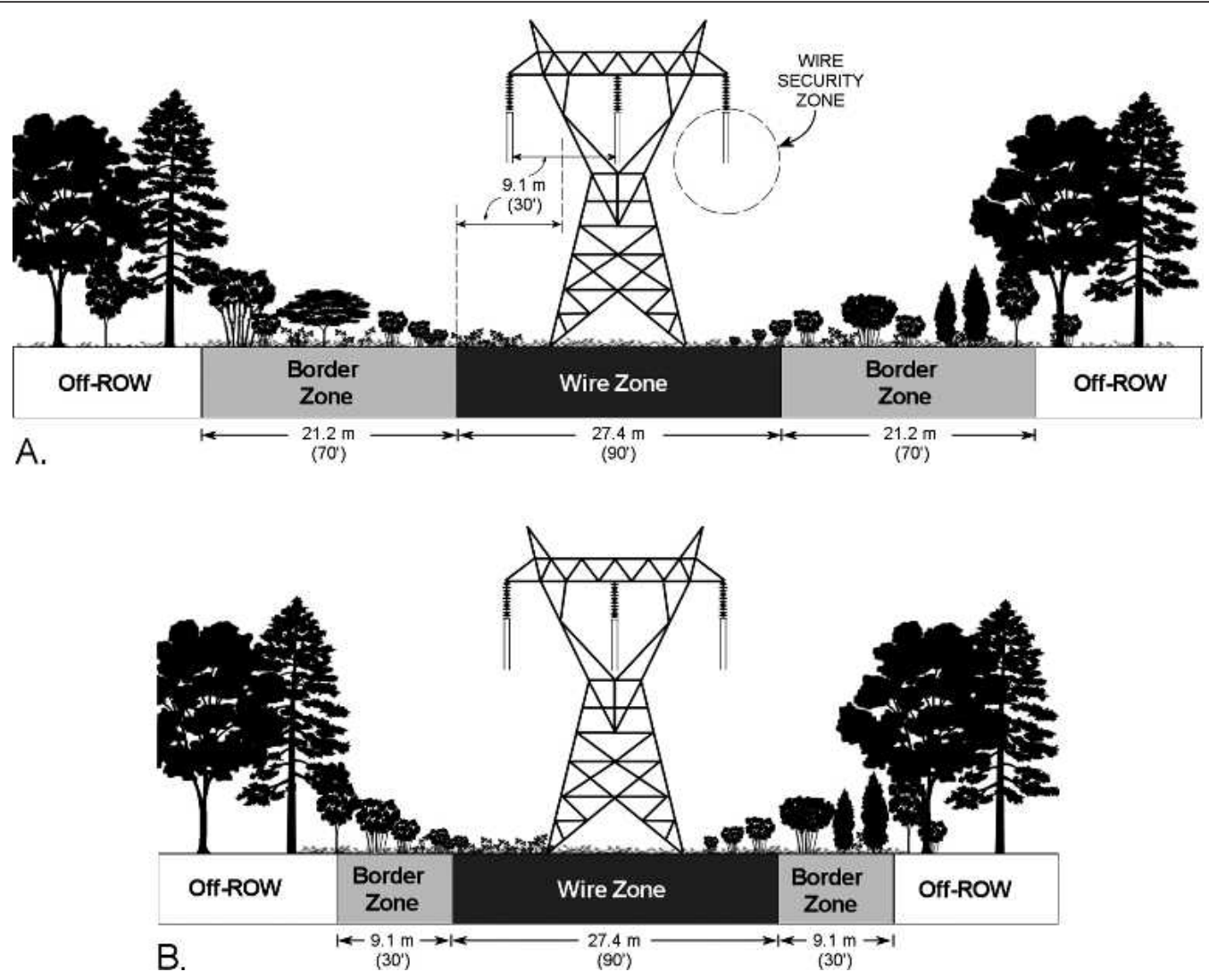

Figure 1. Site-explicit division of a powerline right-of-way (ROW) cross-section into three zones: the border zone (BZ), the wire zone (WZ), and another BZ. (A) ROW cross-section based on Bramble et al. $(1985,1986)$ figure dimensions (atypical), scaled for a 345-kV powerline with a horizontal conductor configuration. (B) ROW cross-section redrawn with a more conventional ROW width for a 345-kV powerline with a horizontal conductor configuration. The WZ for both figures was determined using the distance between conductors $(9.1 \mathrm{~m} \mathrm{(30} \mathrm{ft)} \mathrm{in} \mathrm{this} \mathrm{case).} \mathrm{Wire} \mathrm{security} \mathrm{zone} \mathrm{(and} \mathrm{on-the-ground}$ WZ) dimensions may vary by regulatory requirements and site- or ROW-specific considerations. Woody vegetation was not restricted to the BZ here, because low-growing shrubs can be compatible even in the WZ, depending on access requirements, site topography, and position relative to midspan between tower structures (see Figure 2 ).

tion, i.e., the taller woody shrubs (Figure 2A, "effective border zone"). The "effective border zone" may include BZ as well as WZ with sufficient ground-to-conductor clearances, allowing for more shrub vegetation in ROW plant communities without sacrificing safe and reliable transmission of electricity. Management needs and objectives might still warrant that some or all of the area under the wires in an "effective border zone" (noncritical wire zones) be kept free of most woody vegetation. Those portions of a ROW that must be maintained free of all woody vegetation at all times will vary by ROW dimensions and ground-to-conductor clearances as well as site-specific considerations for access, safe working conditions, structure integrity, stakeholder interests, environmentally sensitive areas, wildlife, and other "integrated" elements of vegetation management. Accord- ing to Dr. Bramble, in the original WZ/BZ approach, which was developed in the context of relatively narrow ROWs as a means to produce a WZ for access (e.g., locating the access road down the middle of the ROW), the intended WZ in which woody cover was excluded could be as narrow as the width of a vehicle (pers. comm., circa 1988). Methods for achieving WZ conditions (i.e., low vegetation; sometimes with low-growing shrubs, sometimes not) include both selective and nonselective methods; however, nonselective methods such as broadcast, broad-spectrum herbicide applications may unnecessarily remove all low-growing woody shrubs along with many desirable nonwoody plants. Other portions of a ROW may warrant the removal of all woody plants. For example, we have defined an "exclusion zone" directly under and surrounding the conductor support struc- 


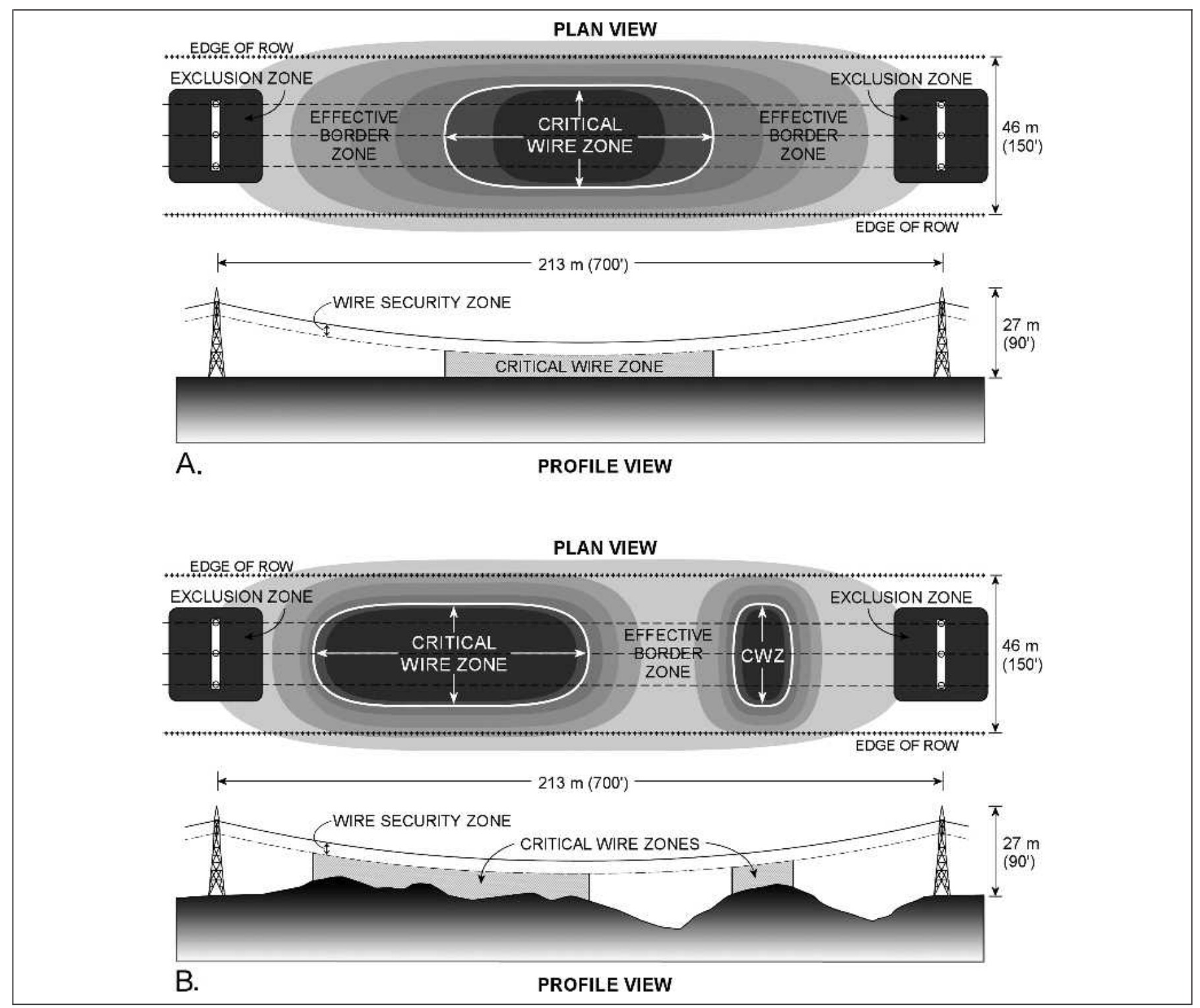

Figure 2. Plan and profile views of $345-\mathrm{kV}$ transmission line rights-of-way (ROW) with a horizontal conductor configuration on (A) level topography and (B) uneven topography with contours of electromagnetic field strength at ground level (adapted from Lee et al. 1993). Greater electromagnetic field strength and corresponding shorter ground-to-conductor clearances are depicted by successively darker zones or contours. The darker zones labeled "critical wire zones" (CWZ) represent areas where tall-growing woody vegetation, shrubs or trees, pose the greatest threat to safe and reliable transmission of electricity (i.e., shortest distances between the ground and conductors or wire security zone). Border zones supporting a mosaic of shrubs and select short trees could be maintained along the edges of the ROW (i.e., border zones, as depicted in Figure 1) and in wire zones where ground-to-conductor clearances are greater ("effective border zones" or noncritical wire zones) such as positions distant from midspan or with low topography as represented by lighter gray areas outside the CWZs in both plan views. Proposed "exclusion zones" are placed around the base of tower structures to assure access for maintenance and repair and to minimize fire hazard. 
tures (towers or poles) to be maintained free of woody vegetation. Maintaining this exclusion zone ensures access for maintenance, repair, and inspection; worker safety; longevity of structures; and so on, and is commonly practiced by many utilities.

In conclusion, the WZ/BZ approach is a potentially useful one, but if it is to be used as an "industry best practice" for Integrated Vegetation Management, consideration should be given for a more accurate and flexible interpretation of this management approach. Specifically, the traditional Bramble et al. depiction of a ROW cross-section should be updated, as depicted in Figure 1B, to more accurately represent typical ROW dimensions, particularly for transmission lines of 230 $\mathrm{kV}$ or greater. Additionally, plan and profile views should be added to represent a three-dimensional system (Figure 2). Plan and profile figures demonstrate that a potentially large area of a ROW can be managed for a mosaic of shrubherbaceous vegetation if $\mathrm{WZ}$ areas with adequate conductorto-ground clearances are managed as "effective border zones" permitting woody vegetation. An exclusion zone may also be warranted around tower structures, in which only nonwoody vegetation is permitted to grow, ensuring access for repair and maintenance and minimizing potential fire hazard, particularly around wooden structures. Using these updated figures for depicting the WZ/BZ approach will allow a broader, more flexible interpretation and implementation of the WZ/ BZ approach, which ultimately, we feel, will be more consistent with Integrated Vegetation Management on electric transmission line ROWs (see further discussion on IVM in Nowak and Ballard 2005).

Although our northeastern United States perspective-one that views shrubs as an important, desirable component of ROWs-may differ from those working in other locales as a result of different regulatory, socioeconomic and environmental conditions, our objective here is to encourage broader interpretation of the WZ/BZ approach. Although shrubs may be an important, desirable component of New York ROWs, we recognize that in some regions, permitting woody vegetation on ROWs may not be a best management practice; best management practices will commonly differ by region.

Acknowledgments. Over the past decade, we have worked collaboratively with various organizations and have gained much in terms of collegial reactions and monetary support that afforded us developmental opportunities such as this. We acknowledge the following organizations for that support: Electric Power Research Institute (EPRI), National Grid (NG), New York Power Authority (NYPA), and New York State Electric and Gas (NYSEG). The following individuals were especially helpful in reviewing and commenting on this research note: Ken Finch (NG), Dick Mider (NYSEG), Dave Morrell (New York State Public Service Commission), Lewis Payne (NYPA), and Tom Sullivan (NG).

\section{LITERATURE CITED}

ANSI. 2006. American National Standards for Tree Care Operations-Tree, Shrub, and Other Woody Plant Maintenance-Standard Practices (Integrated Vegetation Management. A. Electric Utility Rights-of-Way). ANSI A300 (Part 7)-2006. American National Standards Institute, Inc., Washington, DC.

Ballard, B.D., H.L. Whittier, and C.A. Nowak. 2004. Northeastern Shrub and Short Tree Identification-A Guide for Right-of-Way Vegetation Management. Research Foundation of the State University of New York and SUNY College of Environmental Science and Forestry, Syracuse, NY.

Bramble, W.C., W.R. Byrnes, and R.J. Hutnik. 1985. Effects of a special technique for right-of-way maintenance on deer habitat. Journal of Arboriculture 11:278-284.

Bramble, W.C., W.R. Byrnes, and M.D. Schuler. 1986. Effects of a special technique for right-of-way maintenance on an avian population. Journal of Arboriculture 12: 219-226.

CN Utility Consulting. 2004. Utility Vegetation Management Final Report. Commissioned to support the federal investigation of the 14 August 2003 northeast blackout. Federal Energy Regulatory Commission, Washington, DC.

Lee, J.M., V.L. Chartier, D.P. Hartmann, G.E. Lee, K.S. Pierce, F.L. Shon, R.D. Stearns, and M.T. Zeckmeister. 1993. Electrical and Biological Effects of Transmission Lines: A Review. U.S. Department of Energy, Bonneville Power Administration, Portland, OR.

Nowak, C.A., and P.J. Appelt. 2002. Wildlife and Integrated Vegetation Management on Electric Transmission Line Rights-of-Way. Electric Power Research Institute, Palo Alto, CA. EPRI Technical Update No. 1005366.

Nowak, C.A., and B.D. Ballard. 2005. A framework for applying Integrated Vegetation Management on rights-ofway. Journal of Arboriculture 31:29-38.

Nowak, C.A., B.D. Ballard, P.J. Appelt, and D. Gartman. 2002. Integrated Vegetation Management of Gas Line Rights-of-Way. Gas Technical Institute, Chicago, IL, GRI-01/0096.

Yahner, R.H., and R.J. Hutnik. 2004. Integrated vegetation management on an electric transmission right-of-way in Pennsylvania, U.S. Journal of Arboriculture 30: 295-300.

Yahner, R.H., B.D. Ross, R.T. Yahner, R.J. Hutnik, and S.A. Liscinsky. 2004. Long-term effects of rights-ofway maintenance via the wire-border zone method on bird nesting ecology. Journal of Arboriculture 30: 288-294 
Benjamin D. Ballard (corresponding author) Research Scientist

Department of Forest and Natural Resources Management State University of New York College of Environmental Science and Forestry

1 Forestry Drive

Syracuse, NY 13210, U.S.

bballard@esf.edu

Kevin T. McLoughlin

System Forester (retired)
New York Power Authority

Gilboa, NY 12076, U.S.

Christopher A. Nowak

Associate Professor

Department of Forest and Natural Resources Management State University of New York College of Environmental Science and Forestry

1 Forestry Drive

Syracuse, NY 13210, U.S. 